\title{
Vom letzten Zürcher Einhorn zum ersten Schweizer Meersäuli
}

\section{Eberhard Wolff}

PD Dr. rer. soc., Redaktor Kultur, Geschichte, Gesellschaft

Als Conrad Gessner 1554, 38-jährig, Stadtarzt von Zürich wurde, waren die ersten Tausend Seiten seiner Tier-Enzyklopädie gerade erschienen. Tausende weitere Seiten der damals einzigartigen und bis heute berühmten Historia Animalium sollten folgen. Doch bevor er das Nachfolge-Projekt einer Historia Plantarum abschliessen konnte, starb er an der Pest. Zu seinem 500. Geburtstag erinnern zwei Ausstellungen in Zürich an ihn. Sie zeigen Gessner als Kind der Frühphase moderner Naturforschung und spannen einen grossen Bogen - vom Einhorn bis zum Meerschweinchen.

\section{Tierbuch und Pflanzen-Enzyklopädie}

Conrad Gessner, dessen langbebarteter Kopf vor allem von der vorletzten 50-Franken-Note bekannt ist, lebte in einer gewaltigen Umbruchphase. Amerika war kurz zuvor von der «Alten Welt» entdeckt worden. Der Buchdruck beschleunigte den Wissensumlauf enorm. Die
Reformation etablierte ein verändertes Wertegefüge. Der Zürcher Gessner studierte in Basel Medizin, lehrte Griechisch in Lausanne und unterrichtete, zurück in Zürich, unter anderem Zwinglis Studenten in Naturwissenschaften. Nebenbei baute er ein grosses $\mathrm{Ge}$ lehrtennetz auf, denn er hatte ein immenses Projekt im Sinn: Das gesamte zeitgenössische Wissen über die

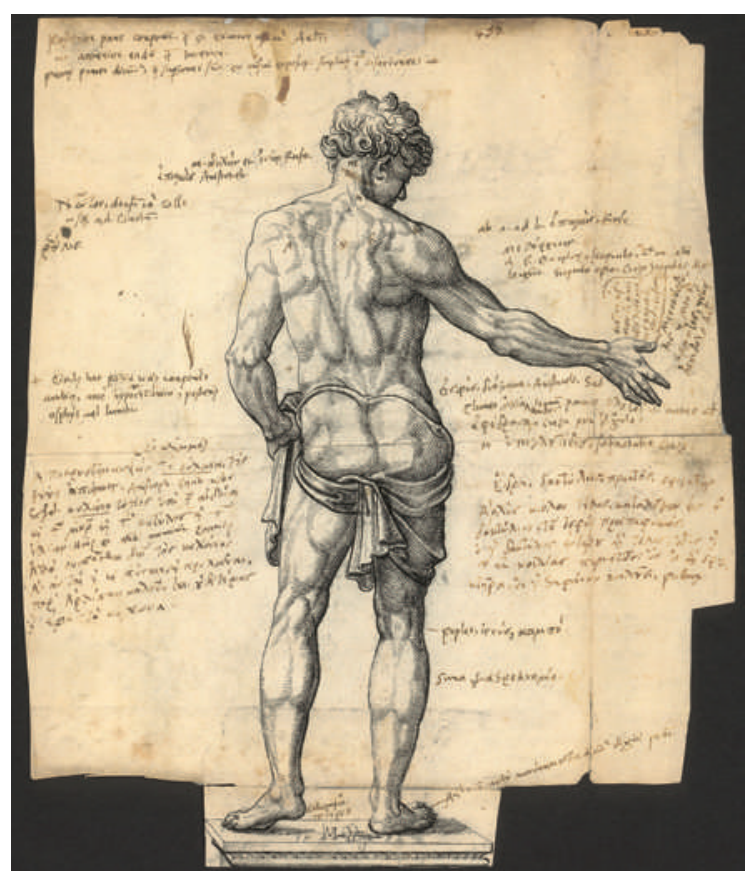

Abbildung 2: Rückenakt mit handschriftlichen Bemerkungen (anatomischen Begriffen) von Conrad Gessner, Jos Murer, 1554. Graphit auf Papier.

(c) Zentralbibliothek Zürich, Handschriftenabteilung, Ms Z VII 118. 
Tiere zusammenzutragen. Ihn interessierte ihr Aussehen, wo und wie sie lebten, ihre «Laster», ihre «Tugenden", wie sie zubereitet werden und - auch als Arzt - wie sie als Medikamente Verwendung finden. Das Tierbuch war für seine Zeit einzigartig, nicht zuletzt mit den über 1000 Holzschnitten, die nicht einfach der Illustration dienten, sondern die naturkundliche Dokumentation unterstützten.

Im Landesmuseum Zürich ist eine Sonderausstellung entstanden, die ihre Besucher eindrucksvoll in Gessners Ära eintauchen lässt. Im Zentrum stehen die wertvollen Bestände der Zürcher Zentralbibliothek. Ein Teil der Ausstellung befindet sich in historischen Räumen aus der Zeit Gessners. Er dürfte sie selbst gekannt haben.

Ein weiteres Highlight der Ausstellung sind die vor einiger Zeit in ausländischen Bibliotheken wiederentdeckten Zeichnungen für seine nie fertiggestellte Pflanzen-Enzyklopädie. Sie sind teils von Gessner selbst angefertigt und weisen ihn als genauen Beobachter aus, der auf eine naturgetreue, aber idealtypische Pflanzendarstellung abzielte.

\section{Fabeltiere}

In der anderen Ausstellung im Zoologischen Museum der Universität Zürich über die Tierbücher stechen zuerst Gessners bekannte «Fabeltiere» ins Auge. Ein Einhorn neben einem Murmeltier, ein «Meermönch» zwischen Gürteltier und Löwe. In Gessners Tierbuch finden sich viele Gestalten, die wir heute ins Reich der Fantasietiere einordnen. War Gessner also doch kein so seriöser Naturforscher? Gastkurator Hans Konrad Schmutz löst die Frage überzeugend auf. Gessner ist ein Kompilator im Übergang zwischen antiker Gelehrsamkeit und neuzeitlicher Tierbeobachtung. Er übernimmt das Wissen von den alten Autoritäten, oft von Aristoteles. Gleichzeitig hält Gessner fest, was er mit eigenen Augen gesehen hat. Und er verarbeitet das Wissen aus zeitgenössischen Veröffentlichungen und Briefen von Kollegen. Der Löwe war in der Antike bekannt, Gessner stützt sich hier auf die antiken Quellen. Über das Gürteltier kann er dort nichts finden, weil es aus der «Neuen Welt» stammt. Aber er erhält von seinen Informanten Skizzen, Beschreibungen und einen echten Panzer des Tiers. Darauf kann er aufbauen. Gessner bekommt von einem Augsburger Kollegen auch die beiden ersten Meerschweinchen der Schweiz («Indianisch Künele») geschenkt und zeichnet sie detailgetreu ab. Ein Panzernashorn hat Gessner nie gesehen, aber er kennt den Stich von Albrecht Dürer, vertraut der Abbildung und orientiert sich daran bei seinem «Rhinoceros». Der 1546 bei Malmö angeschwemmte «Meermönch» ist ein grosses Medien-Thema in Gessners Zeit. Viele Ein-

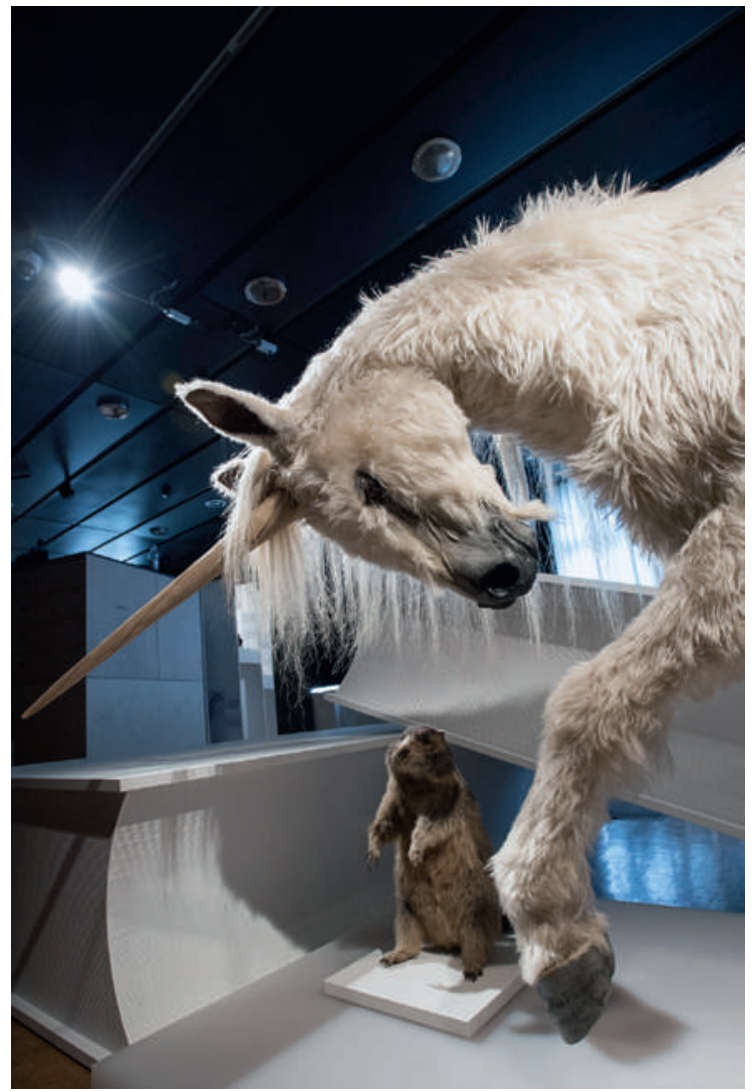

Abbildung 3: Gessner bestätigte das Einhorn. Erst später wurde bekannt, dass dessen Horn der Zahn des Narwals ist. (Bild: Zoologisches Museum der Universität Zürich)

blattdrucke bilden ihn ab. Vom Einhorn gibt es die Hörner in Kuriositäten-Sammlungen und das Pulver daraus in den Apotheken. Für den gläubigen Gessner ist die Natur ein Werk Gottes, und selbst Wunder sind so denkbar. Allerdings ist Gessner skeptisch, wägt ab, übernimmt auch das für ihn Unsichere in sein Buch. Letztlich zweifelt er in seinem Tierbuch an der Existenz des Meermönchs, bestätigt aber das Einhorn und den Basilisken. Erst nach Gessners Tod folgt das Einhorn endgültig dem Weg des Meermönchs, das Horn des Einhorns wird dem Narwal zugeordnet.

Gessners Tier-Enzyklopädie lebte auf dem Buchmarkt noch lange weiter. Sein Drucker Froschauer gab immer wieder neue Ausgaben heraus. Auch auf Deutsch, mit vielen Holzschnitten und weniger Text. Und mit viel mehr Einhorn-Abbildungen.

Die Sonderausstellung im Landesmuseum Zürich ist bis 19. Jun zu sehen, diejenige im Zoologischen Museum der Universität Zürich bis 11. September. Weitere Informationen, auch zu zwei neuen Büchern zum Thema und einer Tagung (6.-9. Juni), via www.gessner500.ch 